\title{
Water harvesting for young trees using Peltier modules powered by photovoltaic solar energy
}

\author{
M.A. Muñoz-García , G.P. Moreda, M.P. Raga-Arroyo, O. Marín-González
}

\begin{abstract}
A B S T R A C T
Young trees transplanted from nursery into open field require a minimum amount of soil moisture to successfully root in their new location, especially in dry-climate areas. One possibility is to obtain the required water from air moisture. This can be achieved by reducing the temperature of a surface below the air dew point temperature, inducing water vapor condensation on the surface. The temperature of a surface can be reduced by applying the thermoelectric effect, with Peltier modules powered by electricity. Here, we present a system that generates electricity with a solar photovoltaic module, stores it in a battery, and finally, uses the electricity at the moment in which air humidity and temperature are optimal to maximize water condensation while minimizing energy consumption. Also, a method to reduce the evaporation of the condensed water is proposed. The objective of the system is to sustain young plants in drier periods, rather than exclusively irrigating young plants to boost their growth.
\end{abstract}

\section{Introduction}

In dry-climate areas, transplanting of young container trees from the nursery into commercial orchards faces a critical period during the weeks following the transplant date. A minimum amount of rainfall or irrigation water is required to avoid transplanting shock, i.e. the plant roots successfully in its new location. Ideally, in non-irrigated orchards the transplant date should be matched to the value of the soil water reserve. However, sometimes the choice of transplant date is not possible. During drier periods the soil water reserve is negligible, so the value of the irrigation water requirement is given by the crop evapotranspiration $\left(\mathrm{ET}_{\mathrm{c}}\right)$.

$\mathrm{ET}_{\mathrm{c}}$ can be defined as the total amount of water lost in a plant as a result of two separate processes: evaporation and transpiration. The evaporation process occurs in the surface of the water of the soil. Water is also lost from the crop by transpiration trough plant stomata. Evaporation and transpiration occur simultaneously and there is no easy way of distinguishing between the two processes. When the crop is small, water is predominantly lost by soil evapo- ration, but once the crop is well developed and completely covers the soil, transpiration becomes the main process (FAO, 1998).

Conventional irrigation methods use rainfall after is has infiltrated in the ground, using underground water or water from streams and rivers (Prinz, 2002). Another source of irrigation water is treated domestic and industrial non-toxic wastewater. Furthermore, we can consider a 'non-classical' water source, viz. air moisture. The moisture from the air can be obtained by three main methods: cooling a surface below the dew point, using a solid or liquid desiccant or controlling the air convection inside a tower (Wahlgren, 2001). Air moisture harvesting can be subdivided into fog harvesting and dew harvesting. Fog water collection by trees (Gioda et al., 1992) or by synthetic nets is very useful in the low mountain regions close to the ocean, such as the Canary Islands. Likewise, fog harvesting is an important source of water supply in some rural areas of Nepal (NEWAH, 2005).

Dew can be defined as atmospheric water vapor condensation. It is a weather phenomenon that occurs spontaneously in nature, and it requires a cold surface, cooler than the surrounding air. A requisite for dew formation is a drop in temperature below the so-called dew point temperature. The formation of dew requires a cold surface, however $100 \%$ air humidity is not necessary. In fact, dew is common even in the drier zones of our planet (Nikolayev et al., 1996). Dew point temperature depends not only on air humidity but also on air temperature. In the Canary Island of Lanzarote there is a traditional growing system for vineyards. The individual plants are grown in shallow depressions or holes dug in the ground which apart from protecting the plant from the dry Sahara 
desert wind, favors dew condensation. In a study conducted by Jacobs et al. (2006), dew was observed to contribute about $4.5 \%$ of the mean annual precipitation in the Wageningen University (Netherlands).

By mimicking Nature, it is possible to design passive dew condensers to promote atmospheric water vapor condensation without using any external energy. Some examples of passive dew condensers can be found in the literature (Nilsson, 1996; Muselli et al., 2002). All these devices try to optimize the passive dew condenser design in order to maximize dew collection. The temperature of a passive condensing surface depends on several factors. For example, heat exchanges can take place by conduction with the ground or the atmosphere itself and through radiation. The present condensation process must also be taken into account, accompanied by latent heat production that increases the temperature of the passive condensing surface. Radiative exchanges have two antagonist actions: heating (by solar radiation) and cooling (primarily in the infrared field). During the day, the heating prevails over the cooling. At night, the reverse is true and the passive condensing surface cools down (Beysens and Milimouk, 2000). When passive dew condensation occurs in a greenhouse, it can result in the formation of fungi (Köner and Challa, 2003).

\section{Objectives}

In this work we test a 'non-conventional' method for obtain water that could be used to water young trees by obtaining water from the air. The objective of the system reported herein is to obtain the water required by some dry-climate woody crops to overcome their critical growing stage. The method we propose is extracting water from air using the thermoelectric effect. The thermoelectric effect can be defined as the direct conversion of temperature differences to electromotive force (EMF) and vice versa. When the effect is harnessed in the first direction, as in thermocouples, it is called the Seebeck effect. When the effect is harnessed in the opposite direction it is called the Peltier effect. In our research we have used the Peltier effect with the goal of condensing air humidity. Unlike the passive dew condensers previously mentioned, our condensing system is an active one. Therefore, the condensing system consumes energy. To make the system autonomous, the electric current required by the Peltier modules is generated by a solar photovoltaic module (SPVM). Since the SPVM only generates during daylight hours, the electricity generated by the SPVM is stored in a battery. The main objective of the experiment is to evaluate the effectiveness of this method, the best conditions to operate it, and so evaluating:

- The algorithm to control the system to optimize energy consumption versus the water obtained.

- The energy consumption in different conditions of relative humidity and air temperature.

- The size of both the SPVM and the battery.

\section{Materials and methods}

\subsection{Peltier effect and Peltier devices}

The Peltier effect consists of the application of an EMF to the junction of different materials, which results in a temperature difference. In the same EMF, semiconductors are more efficient than metals in obtaining a high temperature difference. In the junction of two different doped semiconductors, known as N-type and Ptype depending on the negative or positive valence of the doper, a cold and a hot side appear (Fig. 1).

A Peltier module is made of many semiconductor unions in order to achieve a high temperature difference between both sides of the module. The temperature difference will also depend on proper cooling of the hot side, otherwise heat will flow from the hot to the cold side and the device will not work correctly. The thermoelectric elements and their electrical interconnections typically are mounted between two ceramic substrates. The substrates hold the overall structure together mechanically and electrically insulate the individual elements from one another and from external mounting surfaces.

Common Peltier module configuration includes from 32 to 256 single unions, and will achieve a temperature difference of about $70{ }^{\circ} \mathrm{C}$ when the hot side is at $50^{\circ} \mathrm{C}$ (the cold side would be at $-20^{\circ} \mathrm{C}$ ). The electrical power required by a $30 \mathrm{~mm} \times 30 \mathrm{~mm}$ module that reaches a temperature difference of $70^{\circ} \mathrm{C}$ is about $20 \mathrm{~W}$, while the required power for a $40 \mathrm{~mm} \times 40 \mathrm{~mm}$ module is close to $80 \mathrm{~W}$. Fig. 2 shows the typical in-series configuration of a number of single unions to form a complete Peltier module.

\subsection{Experimental system layout}

The final goal of the experimental system was to determine the effectiveness of an autonomous Peltier-effect-based system to obtain water that help young trees survive. This goal entailed the need for devices which detect the Peltier modules energy con-

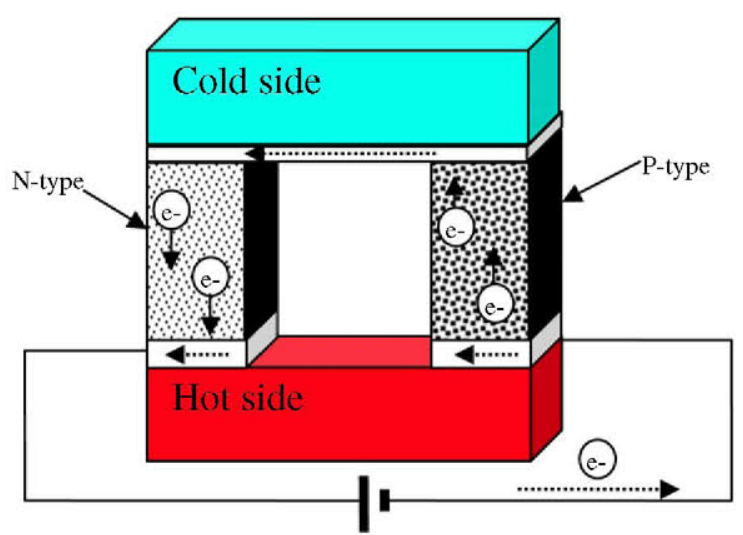

(a)

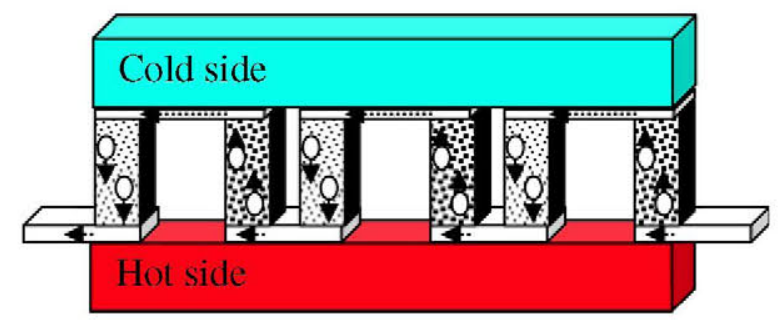

(b)

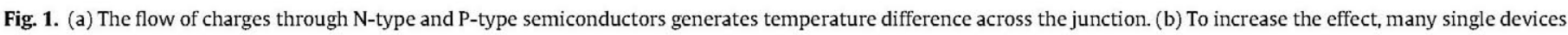
are connected in series. 


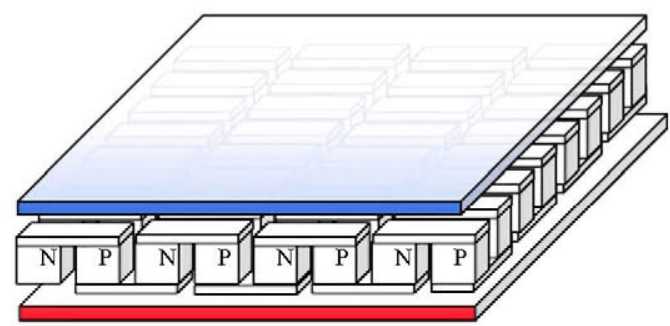

Fig. 2. Configuration of a number of in-series connections of single union devices to form a Peltier module.

sumption and for undertaking a precise temperature control. A data acquisition board (DAQB) connected to a notebook computer was used. Furthermore, the notebook computer was used for measuring the volume of water harvested and for recording the values of the ambient variables (namely, air temperature and relative humidity). A solar photovoltaic (SPV) power system was utilized in order to assess the autonomy of both the condenser and the computerized data acquisition.

Fig. 3 shows the main parts of the experimental system developed, which consisted of:

- An autonomous power source, comprised in turn of SPVM, battery, and battery charge controller, model Sunsaver MPPT, manufactured by Morning Start. The SPVM used was a c-Si based module with a rated power of $145 \mathrm{~W}$ manufactured by Isofoton. The battery was a $12 \mathrm{~V}$ lead-acid battery with a capacity of 102 A h, model 102 A BE1024 manufactured by Delphi Freedom.

- A control system, and

- The condensing system or condenser.

Quantification of the volume of water harvested required periodic visual inspection. To automate the task, a webcam was installed which recorded the water accumulated on an hourly basis. Further data analysis showed the relationship between the volume of water harvested and the electrical consumption.

\subsubsection{Control system}

The computer controlled the energy that reached the Peltier modules by means of digital outputs from a USB controlled data acquisition board. To control the power and measure the current that entered each Peltier module, a dedicated electronic circuit was developed. Power transistors switched the current which were controlled by a computer program. The program consisted of a closed loop strategy that took into account the temperature of both sides of the Peltier modules.

The wiring diagram of the experimental system electronic control circuit is shown in Fig. 4.

Once the Peltier modules are switched on, the control strategy is executed by the following: the duration of the Peltier modules "on" status is proportional (by means of the proportional action in a PID control) to the difference between the actual temperature of the condensing surface and the set-point temperature calculated by the software $\left(T_{s}\right.$, Eq. (3)). Its function can be compared to a PWM control. It must be pointed out that if the integral and differential parts of the PID control are not implemented, the steady state error will occur. Nevertheless, the proportional control met the precision standards for the purpose of this study. When the system was in the "on" state, the voltage of the battery was applied to the modules, passing through the power transistors and measured (using the shunt resistors of the test points in Fig. 4) by data acquisition. The flow chart of the LabVIEW program is shown in Fig. 5. An extra function was included in the program to control the temperature of the hot side of the condenser in order to avoid an exceeding high temperature that could damage the Peltier modules.

\subsubsection{Condenser}

The experimental condenser is represented schematically in Fig. 6, and an actual picture is shown in Fig. 7. The elements that formed the condenser were arranged in a wooden case, which

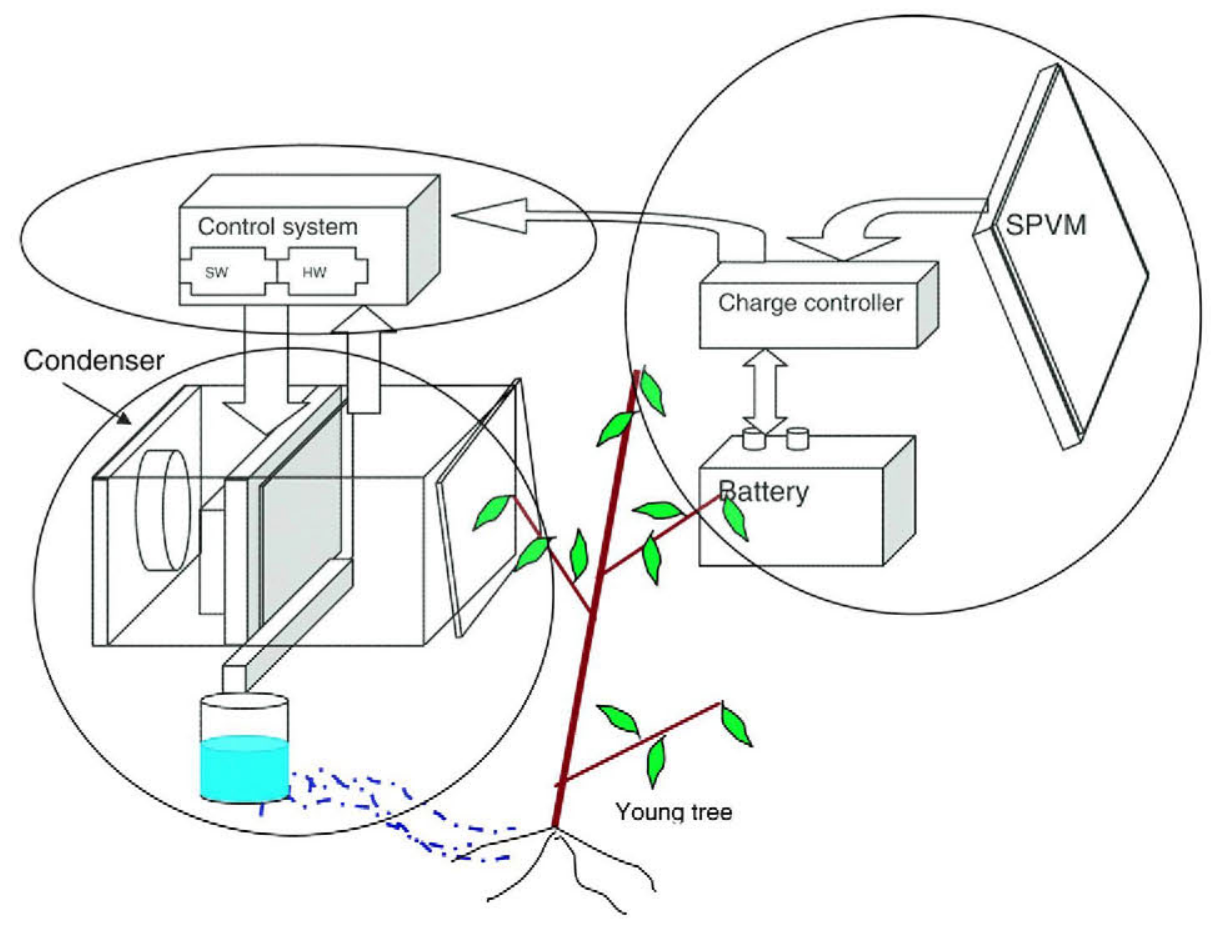

Fig. 3. Experimental system layout. SW and HW are, respectively, the software and hardware of the control system. SPVM is the solar photovoltaic module. 


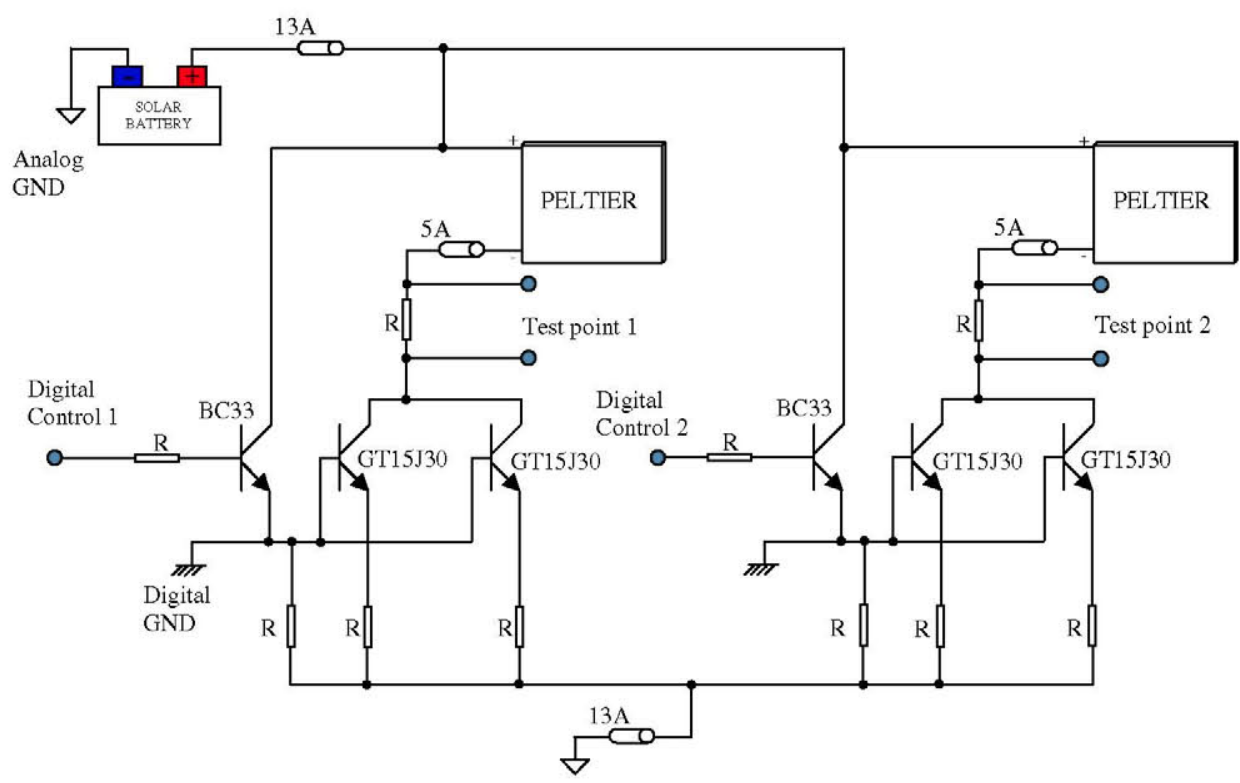

Fig. 4. Simplified wiring diagram of the electronic control circuit. Test points and digital controls are connected to analog inputs and digital outputs of the National Instruments DAQ

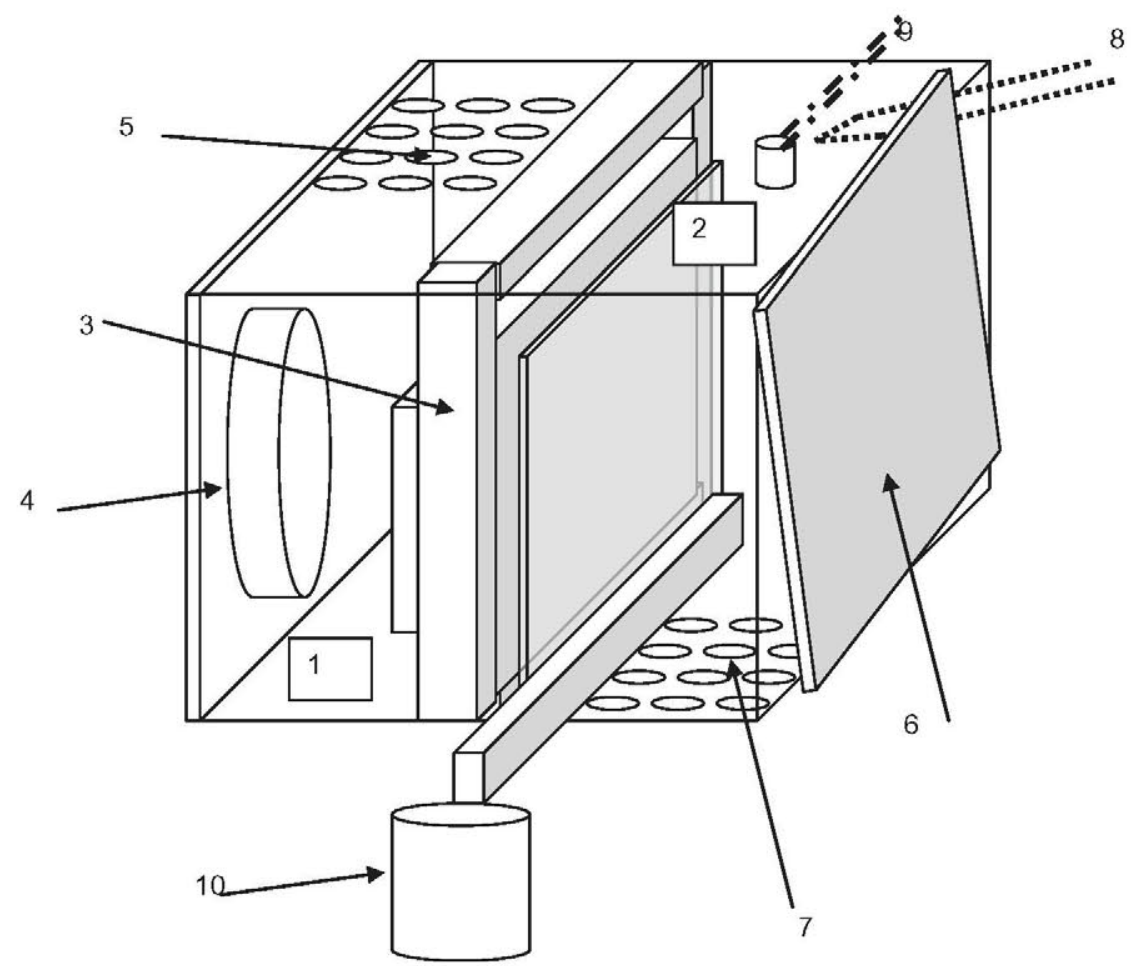

Fig. 5. Simplified flow chart of the LabVIEW program that controls the system.

safely enclosed the machine. The wooden case was placed in a metal case (not depicted in Fig. 6) to protect the entire condenser.

The wooden case was divided in two chambers: The cold chamber (' 2 ' in Fig. 6), where the condensation occurred, and the hot chamber ('1' in Fig. 6). Both chambers were separated by the frame or structure containing the Peltier modules (3). The hot chamber requires a fan (4) to reduce the temperature by air flowing through holes at the top of the chamber (5). In the cold chamber the air inlet aperture can be modified, (6) depending on the air flow needed. Once the air has been cooled and dried, it will flow out through the perforated bottom (7). To determine the dew point temperature, it is necessary to use an air temperature sensor (8) and a relative humidity sensor (9). Once the water is condensed on the cold surface, it is drained into a vessel (10).

3.2.2.1. Peltier modules and heat dissipation. A major pitfall in a cooling system based on the Peltier effect is the temperature of the Peltier module hot side. If the temperature of the hot side reaches the melting point temperature of the solder, the Peltier module will be destroyed. If the temperature of the hot side equals 

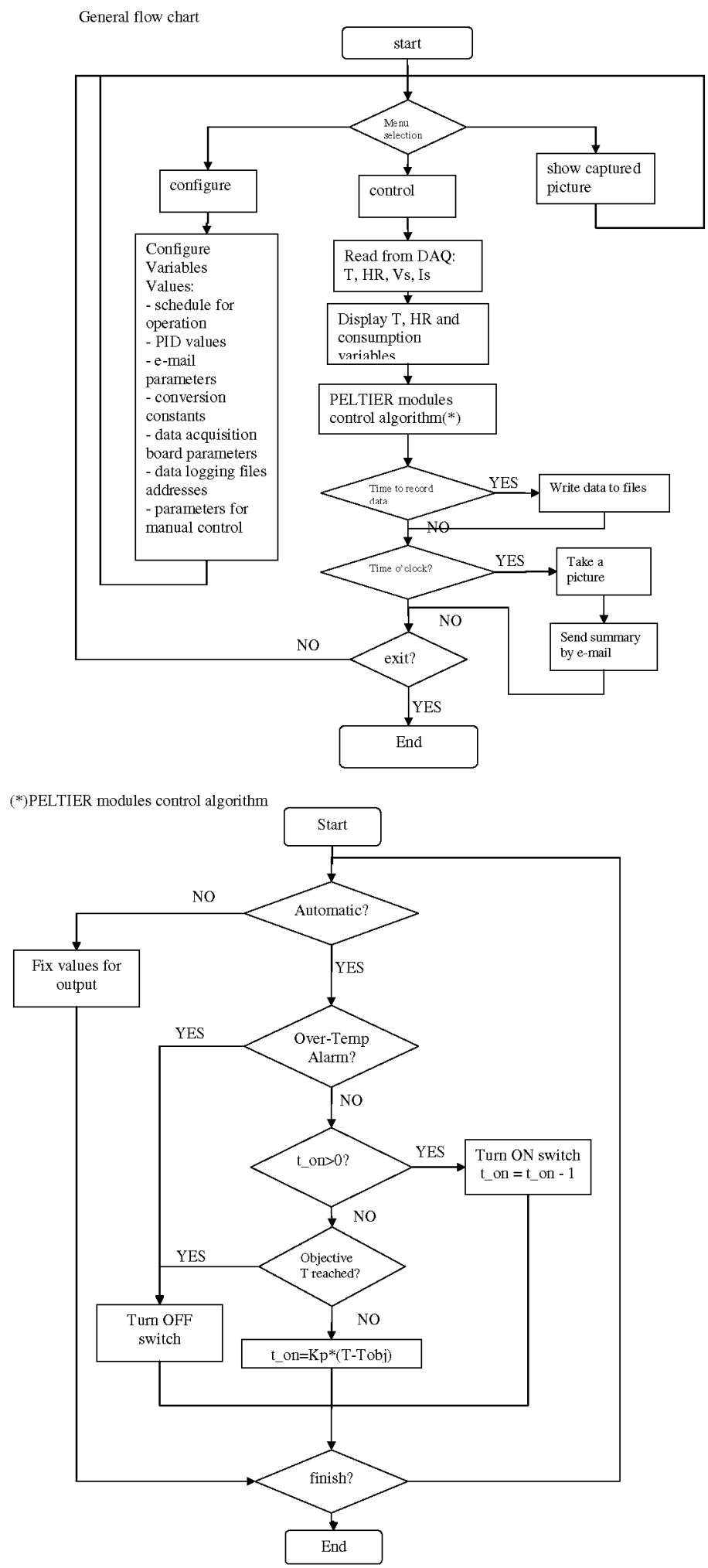

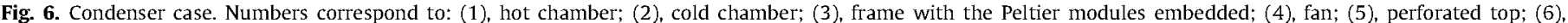
adjustable lateral board; (7), perforated bottom; (8), cold chamber air temperature sensor; (9), relative humidity sensor; and (10), vessel.

that of the cold side, the cooling effect will not occur. Therefore, heat must be dissipated and a precise temperature control must be performed.

The main element for dissipating the heat was a low-thermalresistance aluminum heat sink based on a configuration that allows maximum air flow through the hot surface. The two Peltier modules were embedded inside a thermal isolating structure to avoid heat transfer from the hot side to the cold side. The temperature of the hot side was monitored by means of a thermocouple to avoid reaching the melting point temperature of the Peltier modules. Thermal resistance of the heat sink was $0.08^{\circ} \mathrm{C} / \mathrm{W}$. The outer dimensions of the heat sink were $101.6 \mathrm{~mm} \times 100 \mathrm{~mm} \times 32 \mathrm{~mm}$. 


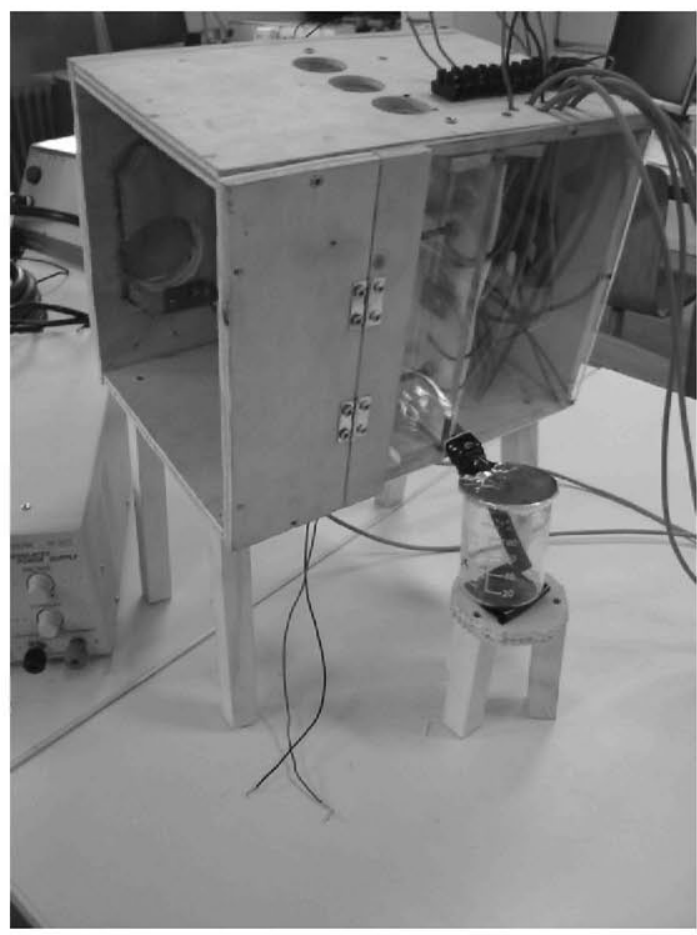

Fig. 7. The experimental condenser.

Thermally conductive silicone grease was used to reduce thermal resistance of the contact between the hot side of the Peltier modules and heat sink. To reduce the temperature further, a $6 \mathrm{~W} / 12$ VDC fan was installed that generated an air flow throughout the heat sink.

3.2.2.2. Dew point temperature calculation and temperature control. In order to use the exact energy to condense water, a precise control of the temperature of the cold side must be performed. Three thermocouples were used and their average temperature was calculated every $10 \mathrm{~ms}$ to control the electrical energy transferred to the condenser. The temperature of the cold side was quite homogeneous due to the attachment of an aluminum surface. This surface was covered with an anti-moisture liquid manufactured by Proquimetal, to reduce the water tension and improve condensed water run-off.

Data from the sensors were read from a data acquisition board connected to a notebook computer and running a program developed with LabVIEW ${ }^{8}$. The dew point temperature was calculated according to Eq. (1):

$T_{\mathrm{dp}}=\sqrt[8]{\frac{H_{\mathrm{r}}}{100}} \cdot\left(112+0.9 \cdot T_{\mathrm{a}}\right)+0.1 \cdot T_{\mathrm{a}}-112$,

where $T_{\mathrm{dp}},\left({ }^{\circ} \mathrm{C}\right)$ is the dew point temperature, $H_{\mathrm{r}},(\%)$ is relative humidity and $T_{\mathrm{a}}\left({ }^{\circ} \mathrm{C}\right)$ is the temperature of the air moisture to be condensed, i.e. the air in the cold chamber.

For example, for $H_{\mathrm{r}}=10 \%$ and $T_{\mathrm{a}}=25^{\circ} \mathrm{C}, T_{\mathrm{dp}}$ is $-8.77^{\circ} \mathrm{C}$, whereas for $H_{\mathrm{r}}=90 \%$ and $T_{\mathrm{a}}=50^{\circ} \mathrm{C}, T_{\mathrm{dp}}$ is $47.90^{\circ} \mathrm{C}$.

LabVIEW is an adequate tool to create programs to control processes and obtain data (data logging). LabVIEW programs are used to control processes that involve temperature and humidity (Speetjens et al., 2008) or even data acquisition that includes images.

\subsubsection{Water harvester}

There are some patented systems that use Peltier modules to condensate water from the air (Biancardi, 1982; Smith, 1984; Zolnier et al. 2000; Zhang, 2003; Hatamian and Ghalebi, 2007).

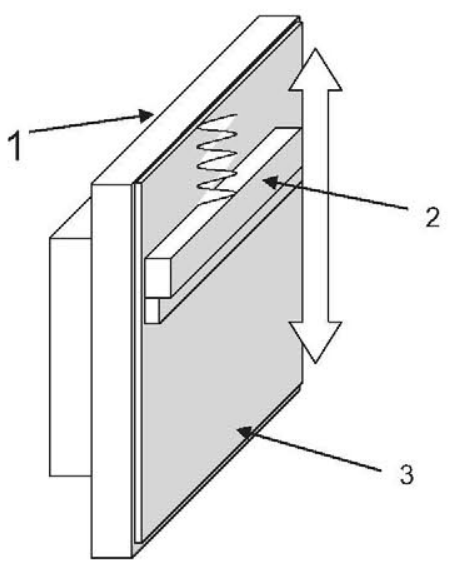

Fig. 8. The proposed solution to harvest the water before it converts to water vapor. (1) Peltier modules structure, (2) slide, (3) condensing surface.

However, most systems do not use computer-based control and the ones that use it do not have a method to prevent water evaporation before it can be harvested.

According to the results of the experiment, two conditions that impede a system which obtains water from the air include the heat and dryness of the air. Water transforms to its gaseous state if it is not harvested immediately. The solution consists of a slide that helps the condensed water to be harvested from the cold side of the condenser before it passes back to vapor state (Fig. 8).

The slide would cover the cold surface in order to prevent evaporation and would direct water to the root of the tree (Muñoz-García et al., 2012).

\subsection{Data acquisition}

According to Fig. 5 the program in the notebook registered the temperature of the different parts, the ambient variables $\left(T_{\mathrm{a}}\right.$ and $H_{\mathrm{r}}$ ) and the system energy consumption, in addition to controlling the condenser system. Moreover, the volume of water harvested every hour was manually measured, and supported by a webcam that took a picture of the graduated cylinder every hour. The measurements of the consumption of the Peltier modules and the environmental data (temperature and relative humidity) were read by the program using two DAQBs manufactured by Measurements and Computing.

System energy consumption data as registered by the notebook computer was compared to the data stored in the memory of the battery charge controller accessed via the device display.

\section{Results and discussion}

The experimental system was tested in September 2010. The following data was registered daily: air temperature and relative humidity, electrical energy generated by the SPVM, system energy consumption, and the volume of water collected hourly.

Hereinafter, we define temperature difference (TD) as the difference between air temperature, $T_{\mathrm{a}}$ (measured with sensor ' 8 ' in Fig. 6) and the temperature of the condensing surface, $T_{S}$ (calculated as the average of measurements delivered by three thermocouples). Mathematically,

$\mathrm{TD}=T_{\mathrm{a}}-T_{\mathrm{s}}$

TD is an important parameter that is considered in other related applications such as thermoelectric coolers and its maximum depends on the chosen Peltier module (Chatterjee and Pandey, 2003). Using the signals from the sensors, the software calculates $T_{\mathrm{dp}}$ (Eq. (1)) and ensures that $T_{\mathrm{S}}$ reaches a temperature equal to 


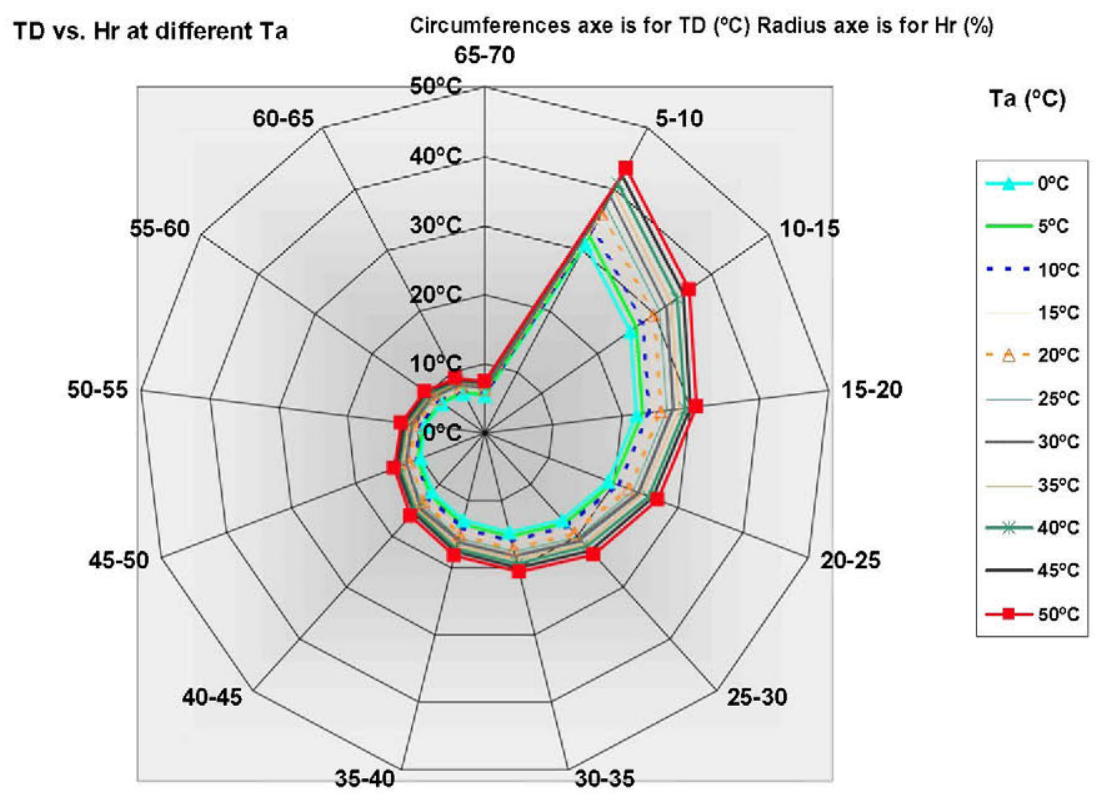

Fig. 9. Relationship between temperature difference (TD) required for dew formation and air temperature $\left(T_{\mathrm{a}}\right)$ and relative humidity $\left(H_{\mathrm{r}}\right)$.

Table 1

Temperature difference $\left(\mathrm{TD},{ }^{\circ} \mathrm{C}\right)$ for recommended thresholds of air temperature $\left(T_{\mathrm{a}}\right)$ and relative humidity $\left(H_{\mathrm{r}}\right)$.

\begin{tabular}{lll}
\hline$T_{\mathrm{a}}\left({ }^{\circ} \mathrm{C}\right)$ & $H_{\mathrm{r}}(\%)$ & \\
\cline { 2 - 3 } & $15-20$ & $65-70$ \\
\hline 0 & 22 & 5 \\
50 & 30 & 8 \\
\hline
\end{tabular}

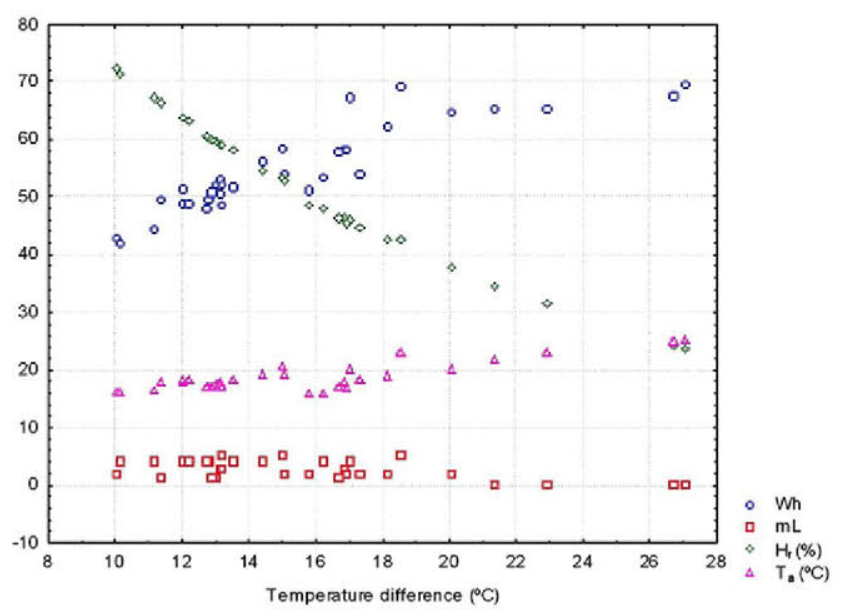

Fig. 10. Energy consumption $(\mathrm{Wh})$, volume of condensed water $(\mathrm{mL})$, relative humidity $\left(H_{\mathrm{r}}, \%\right)$ and air temperature $\left(T_{\mathrm{a}},{ }^{\circ} \mathrm{C}\right)$ versus temperature difference $\left({ }^{\circ} \mathrm{C}\right)$.

$T_{\mathrm{dp}}$ minus a constant of $4^{\circ} \mathrm{C}$. The temperature constant is needed to account for some small extra consumption, thereby guaranteeing that condensation will effectively occur. Mathematically,

$T_{\mathrm{s}}=T_{\mathrm{dp}}-4$

Using the set-point temperature $\left(T_{S}\right)$ and the cold side temperature, the program determines the time the Peltier modules must be connected.

To minimize energy consumption, water harvesting operation was restricted to nocturnal hours, particularly between 05:00 AM and 08:00 AM. Fig. 9 represents the required TD for a given $T_{\mathrm{a}}$ and $H_{\mathrm{r}}$. According to Fig. 9, optimal conditions should be within the range shown in Table 1.

Fig. 10 shows a reverse relationship between relative humidity and condenser energy consumption. As $H_{\mathrm{r}}$ increases, energy consumption decreases and conversely, lower $H_{\mathrm{r}}$ is associated to higher energy consumption. However, there is a practical limit. When $H_{\mathrm{r}}$ is too low, the volume of water condensed is negligible, regardless of the amount of energy supplied to the Peltier modules. According to Fig. 9 and Fig. 10 when $H_{\mathrm{r}}$ is lower than $20 \%$, the temperature difference necessary to obtain water would be more than $20^{\circ} \mathrm{C}$ in all the cases, which could not be reached by this system.

For example, a TD of $15^{\circ} \mathrm{C}$ required approximately $60 \mathrm{~W}$ of power ( $60 \mathrm{~W}$ h of energy in $1 \mathrm{~h}$ ) and the corresponding water volume collected in $1 \mathrm{~h}$ ranged from $2 \mathrm{~mL}$ to $4 \mathrm{~mL}$, depending on $T_{\mathrm{a}}$ and $H_{\mathrm{r}}$ during the night (Fig. 10). Taking into account that a PV module of $30 \mathrm{~W}$ is able to supply up to $180 \mathrm{~W}$ h on a sunny summer day, we hypothesize that such a PV module would have the capacity to generate the energy required to condensate around $10 \mathrm{~mL}$ of water. As the experiment was carried out in Madrid, where the summer is dry and hot, it is expected that the water obtained in ideal conditions would require less energy.

\section{Summary and conclusions}

An experimental autonomous active dew condenser based on the thermoelectric effect and powered by solar photovoltaic energy has been designed and tested. The desired outcome of the system is to maximize the volume of condensed water while energy consumption remains at a minimum. The following conclusions can be drawn:

- The morning hours between 05:00 AM and 08:00 AM were found to the best period of the day for collecting water.

- Water condensation in the experimental system developed is not practical for air relative humidity lower than $20 \%$ (even in the morning).

- A key aspect of the experimental system is the natural tuning between the energy supply and the water demand. Thus, in the drier periods with maximum irrigation levels, the solar 
energy collected reaches a maximum as well. In such conditions, when using a $30 \mathrm{Wp}$ photovoltaic system as the power source, and a $12 \mathrm{~V}$ battery with $17 \mathrm{~A}$ h of capacity, an estimated $10 \mathrm{~mL}$ of water can be obtained.

- If the system is to be used in dry climates, a conductor with a better external thermal isolation in addition to a heat sink with lower thermal resistance should be implemented.

Future works should focus on testing the experimental system under various weather conditions for the course of a year. Also an embedded system should be developed, using a microcontroller and a better isolated chamber for the condenser. The latest reduction in the cost of photovoltaic modules and an increase in their efficiency will lower the cost of the entire system.

\section{Acknowledgments}

Authors wish to express their gratitude to Multiscan Technologies, for supporting and funding this research; to CIEMAT, for providing the solar photovoltaic module, and to the E.U.I.T. Agrícola (Universidad Politécnica de Madrid), for rendering the facilities where the experimental system was mounted.

\section{References}

Beysens, D., Milimouk, I., 2000. Pour des resources alternatives en eau. Sécheresse $11(4), 281-288$.

Biancardi, R.P., 1982. Apparatus and method for automatically watering vegetation. United States Patent US 4 (315), 599.

Chatterjee, S., Pandey, K.G., 2003. Thermoelectric cold-chain chests for storing/ transporting vaccines in remote regions. Applied Energy 76, 415-433.
FAO, 1998. Crop evapotranspiration - guidelines for computing crop water requirements. Available at: http://www.fao.org/docrep/X0490E/x0490e04 htm\#chapter 1 introduction to evapotranspiration (accessed 30.09.11).

Gioda, A., Acosta Baladon, A., Fontanel, P., Hernández Martin, Z., Santos, A., 1992. L'arbre fontaine. La Recherche 23, 1400-1408.

Hatamian, M., Ghalebi, M.A., 2007. Peltier system with water purification means. United States Patent US 11 (799), 622.

Jacobs, A.F., Heusinkveld, B.G., Wichink, R.J., 2006. Contribution of dew to the water budget of a grassland area in the Netherlands. Water Resources Research, 42: W03415, 8

Köner, O., Challa, H., 2003. Process-based humidity control regime for greenhouse crops. Computers and Electronics in Agriculture 39, 173-192.

Muñoz-García, M.A., Van-Olmen, S., Soler-Esteban, A., 2012. System and condenser device for water harvesting from the environment. Spanish Patent ES 2368325.

Muselli, M., Beysens, D., Marcillat, J., Milimouk, I., Nilsson, T., Louche, A., 2002. Dew water collector for potable water in Ajaccio (Corsica Island, France). Atmospheric Research 64, 297-312.

Nepal Water for Health, NEWAH, 2005. Fog water collection in Nepal. Available at: $<\mathrm{http}$ :/www.wateraid.org/documents/fogwater.pdf>. (accessed 30.09.11).

Nikolayev, V.S., Beysens, D., Gioda, A., Milimouk, I., Katiushin, E., Morel, J.-P., 1996. Water recovery from dew. Journal of Hydrology 182, 19-35.

Nilsson, T., 1996. Initial experiments on dew collection in Sweden and Tanzania. Solar Energy Materials and Solar Cells 40, 23-32.

Prinz, D., 2002. The role of water harvesting in alleviating water scarcity in arid areas. In: Keynote Lecture, Proceedings, International Conference on Water Resources Management in Arid Regions, 23-27 March, vol. III, 2002, Kuwait Institute for Scientific Research, Kuwait, pp. 107-122.

Smith, R.H., 1984. Apparatus and method for recovering atmospheric moisture. United States Patent US 4 (433), 552.

Speetjens, S.L., Janssen, H.J.J., van Straten, G., Gieling, Th. H., Stigter, J.D., 2008. Methodic design of a measurement and control system for climate control in horticulture. Computers and Electronics in Agriculture, 64, 162-172.

Wahlgren, R.V., 2001. Atmospheric water vapour processor designs for potable water production: a review. Water Research 35 (1), 1-22.

Zhang, Z., 2003. Automatic semi-conductor condensate flower-watering device. United States Patent US 6 (581), 849.

Zolnier, S., Gates, R.S., Buxton, J., Mach, C., 2000. Psychrometric and ventilation constraints for vapor pressure deficit control. Computers and Electronics in Agriculture 26 (3), 343-359. 